\title{
Geodetection analysis of the driving forces and mechanisms of erosion in the hilly-gully region of northern Shaanxi Province
}

\author{
YUAN Xuefeng ${ }^{1,2,3,4}$, ${ }^{*}$ HAN Jichang ${ }^{1,2}$, SHAO Yajing ${ }^{4}$, LI Yuheng ${ }^{3}$, \\ WANG Yongsheng ${ }^{3}$ \\ 1. College of Land Engineering, Chang'an University, Xi'an 710075, China; \\ 2. Key Laboratory of Degraded and Unused Land Consolidation Engineering, The Ministry of Land and Re- \\ sources, Xi'an 710075, China; \\ 3. Institute of Geographic Sciences and Natural Resources Research, CAS, Beijing 100101, China; \\ 4. School of Earth Science and Resources, Chang'an University, Xi'an 710054, China
}

\begin{abstract}
This paper analyzes the spatial variation in soil erosion in the loess hilly-gully region of northern Shaanxi Province, China. It sums up existing research, describes the factors that drive soil erosion, and uses geodetection to investigate the factors individually and in pairs. Our results show that soil erosion in the loess hilly-gully region of northern Shaanxi is mainly hydraulic erosion. There are significant spatial differences in the severity of soil erosion in the region. Generally, it is more severe in the north and west and less severe in the south and east. Individual factor detection results show that the major risk factors affecting soil erosion are human population distribution, precipitation, land-use type, elevation, and soil type. Interactive detection results show that interacting factors play much bigger roles in soil erosion than do individual factors. Based on forced detection results from different periods of time, we can see that forest and grass coverage, urbanization, and economic development in the study area all clearly inhibit soil erosion.
\end{abstract}

Keywords: soil erosion; driving factors; geodetection; loess hilly-gully region; northern Shaanxi

\section{Introduction}

Soil erosion refers to the process by which soil or the soil-forming parent material is broken up, removed, transported, and deposited. It is the result of both natural and anthropogenic factors (Tang, 2004; Zheng et al., 1995). The effects of soil erosion are deep and long-lasting. As the human population continues to increase and the scope of human activities continues

Received: 2018-07-15 Accepted: 2019-01-10

Foundation: Fund from the Key Laboratory of Degraded and Unused Land Consolidation Engineering, No.214027170087; National Key Research and Development Program of China, No.2017YFC0504705

Author: Yuan Xuefeng, Associate Professor, specialized in land science and rural development.

E-mail: zyxfyun@chd.edu.cn

"Corresponding author: Han Jichang, PhD and Professor, specialized in land science and agriculture and rural development. E-mail: hanjicsxdj@126.com 
to expand, the destruction of the natural environment caused by human activities will greatly exacerbate soil erosion (Liu, 2018).

China's Loess Plateau is one of the regions in the world most seriously affected by soil erosion. As a result, its ecosystems are highly vulnerable (Meng et al., 2008). The loess hilly-gully region of northern Shaanxi Province is located in the center of the Loess Plateau. Erosion-related economic, ecological, and resource crises in the region severely constrain its social and economic development (Liu et al., 2018a, 2008b). Previous research has shown that the major natural factors affecting soil erosion are geology and topography, climate, soil, and vegetation (Liu and Li, 2017). Human factors manifested that accelerated soil erosion was caused by systematic imbalances in the human-land system (Cao et al., 2017), overdevelopment in pursuit of contradictory ends, and urban sprawl (Liu et al., 2018c). Most existing studies on Loess Plateau soil erosion are based on precipitation models (Ding and Huang, 2017), the effects of precipitation and land use on soil erosion (Zhong et al., 2017), the potential for administrative control (Gao et al., 2015), sensitivity analysis (Wang, 2016), temporal and spatial analysis (Xin et al., 2009), administrative techniques (Liu et al., 2014), etc. Relatively little research has been done on the macroscopic causes of erosion. Geodetection is a new tool for geographic research that can effectively analyze spatial differentiation in geographic phenomena and the factors that influence them (Han et al., 2015). In recent years, it has been used to great advantage to study disease risk factors (Wang et al., 2010; Li et al., 2013), agricultural village poverty mechanisms (Liu and Li, 2017), rural space optimization (Yang et al., 2016), urbanization, landscape ecology patterns, urban carbon emissions (Wu et al., 2016), disaster geography (Hu et al., 2011), ecosystems (Luo et al., 2016), etc. There are clear spatial differences in erosion processes, and these are the result of multiple influencing factors. Thus, geodetection, which detects spatial differences and principal causes in geographic phenomena, seems to be an appropriate tool with which to analyze soil erosion. In this paper, therefore, we use geodetection to analyze the spatial patterns and dominant factors influencing soil erosion in the hilly-gully region of northern Shaanxi Province.

Specifically, we use the results of previous soil erosion research to summarize and select the following major factors affecting soil erosion in the study area: land coverage, soil type, soil quality, precipitation, elevation, slope gradient, aspect, population, and Gross Domestic Product (GDP). Based on geodetection, we determine the most important factors influencing soil erosion in the study area and quantify their magnitudes. Then, we use new techniques and new methods to study the region's large-scale soil erosion to broaden and enrich the body of related research.

\section{Methodology}

\subsection{Study area}

The loess hilly-gully region of northern Shaanxi Province is in the middle of China's Loess Plateau between $36^{\circ} 07^{\prime} \mathrm{N}-38^{\circ} 23^{\prime} \mathrm{N}$ and $107^{\circ} 39^{\prime} \mathrm{E}-110^{\circ} 47^{\prime} \mathrm{E}$. It is the second loess hilly and gully sub-region. Administratively, the study area includes Yan'an City, as well as one district and 13 counties in Yulin City (Baota District, Yanchang County, Yanchuan County, Zichang County, Ansai County, Zhidan County, Wuqi County, Ganquan County, Suide 
County, Jiaxian County, Mizhi County, Wubao County, Qingjian County, and Zizhou County) (Figure 1). The study area covers $32,437 \mathrm{~km}^{2}$ with an elevation ranging from $451-1812 \mathrm{~m}$ above sea level. Its higher elevations are found in the north and west and lower elevations in the south and east. For slopes greater than $15^{\circ}$, sloped land takes up $60 \%$ of the area with crisscrossing, fragmented gullies and seriously eroded land. Soil types include juvenile loess, newly deposited soil, and brown loess soil. The topography is mainly a combination of ridges, plateaus, and mounds. The climate is warm temperate, semi-arid with 400-500 mm of annual precipitation. Summer storms are common and can bring over $40 \mathrm{~mm}$ of precipitation in a single event. Seventy percent or more of the annual precipitation falls in the wet season, from June to September. The loess hilly-gully region of northern Shaanxi Province is a transition zone between forest and grassland. It has low vegetation coverage. Land usage is mainly cultivated land and grassland with few wooded areas. Therefore, intense precipitation events during the wet season can easily cause acute erosion.

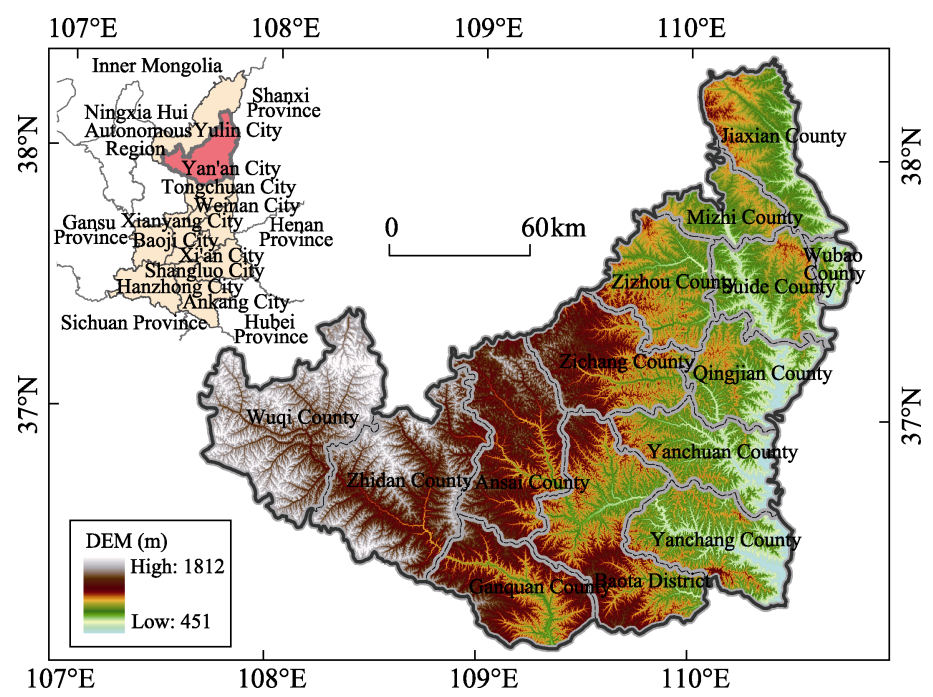

Figure 1 Location and elevation of the loess hilly-gully region of northern Shaanxi Province

\subsection{Data source and processing}

The data in this paper include digital elevation model (DEM) data, soil texture data, soil erosion data and soil-type data for 199, national 1-km grid population data ( $\mathrm{Fu}$ et al., 2014), national 1-km grid GDP data (Huang et al., 2014) and land-use and coverage data (Liu et al., 2014; Liu et al., 2010) of 1995, 2000, 2005, 2010 and 2015, daily precipitation data from the China Meteorological Assimilation Driving Datasets for the SWAT model (CMADS) (Shi et al., 2011; Meng et al., 2016a, 2017) for 1995, and research zone vector boundary data.

Of these, the soil erosion data, population data, GDP data, land-use and coverage data, soil texture data, soil-type data, and vector boundary data come from the resources and environmental science data center of the Chinese Academy of Sciences (CAS) (http://www.resdc.cn), DEM data come from the geospatial data cloud on the computer network information center of CAS (http://www.gscloud.cn). Advanced Spaceborne Thermal 
Emission and Reflection Radiometer Global DEM data have a spatial resolution of $30 \mathrm{~m}$. Precipitation data come from the Heihe Plan Data Center and the Cold \& Arid Regions Scientific Data Center (http://westdc.westgis.ac.cn).

\subsection{Research methods}

This study uses spatial analysis, grid interpolation, natural breakpoints, and geodetection. Spatial analysis is used to extract data on soil erosion, land use, population, GDP, and elevation within the research zone. Soil erosion raster data are converted to $1-\mathrm{km}$ grid data to construct a spatial lattice from which spatial values for each factor are extracted using lattice extraction methods. We use ArcGIS9.3 software's grid interpolation feature to obtain precipitation data by interpolating the maximum daily precipitation recorded at each meteorological station in the study area. We use DEM data to obtain elevation, slope, and aspect data and use natural breaks optimization to reclassify precipitation, soil texture, population, GDP, and slope data to obtain optimal data discretization. Geodetection is used to identify the dominant factors causing soil erosion and quantify their respective effects.

(1) Grid interpolation is a method to estimate continuous data trends from discrete data points using fitting calculations. We tried both the inverse distance weighted interpolation and spline interpolation in ArcGIS9.3 software to interpolate maximum daily precipitation, using data from weather stations in the study area. Inspection of the results indicates that, for our purposes, spline interpolation is superior to inverse distance weighted interpolation. Therefore, we proceeded with the spline interpolation results and discarded the inverse distance weighted interpolation results.

(2) The natural breaks method relies on natural breaks that exist between groups in the data. It uses statistical methods to determine the natural groupings in the data by reducing the average discrete variance within each group and increasing the average discrete variance between groups. It completely relies on the distribution of data. There is no human influence in the process. Natural breaks methods are applied to precipitation, soil type, aspect, GDP, and population data to obtain spatial clustering that meets the requirements for geodetection and discretization of spatial data.

(3) Geodetection is based on the spatial variation in geographic features or phenomena. It uses statistical methods to analyze driving forces. In principle, if some independent variable has a significant effect on some dependent variable, then the spatial distribution of the independent and dependent variables should be similar (Wang et al., 2017).

Geodetection was first used in disease risk assessment (Wang et al., 2010). Geodetectors can detect spatial patterns and mechanisms of causal elements. It is a powerful tool for spatial differentiation analysis (Wang et al., 2016). It has two main advantages over other spatial analysis methods. First, it can deal with both quantitative and qualitative data. Second, it can detect the influence of two interacting independent variables on a certain dependent variable.

Its output includes factor detection, interactive detection, risk detection, and ecological detection. Among these, factor detection is used to determine whether a certain factor is related to the spatial distribution of a certain phenomenon. Interactive detection is used to describe the influence (strengthening or weakening) of interacting factors on the spatial distribution of a certain index. Ecological detection is used to determine whether the effect of 
interacting factors on the spatial distribution of a certain index is significant. It is generally expressed in statistical terms as the value of $F$. Risk detection is used to quantify risks associated with specific factors. It is generally expressed in statistical terms as the value of $T$ (Zhu et al., 2015; Cao et al., 2013). Essentially, this method compares the total variance of an index in different types of areas with its total variance over the entire research zone. It is calculated as follows (Wang and $\mathrm{Xu}, 2017$ ):

$$
q_{x, y}=1-\frac{1}{n \sigma_{y}^{2}} \sum_{i=1}^{m} n_{x, i} \sigma_{y_{x, i}}^{2}
$$

where $y$ is a dependent variable, $x$ is an independent variable, $q_{x, y}$ is the degree to which $x$ explains $y, n$ and $\sigma^{2}$ are the number of samples and the variance, respectively, $m$ is the number of types of a certain factor, and $n_{x, I}$ is the number of samples of index $x$ that are of type $i$. The range of $q_{x, y}$ values is $[0,1]$. When $q_{x, y}=0$, the spatial distribution of $y$ is not affected by $x$. The larger the value of $q_{x, y}$, the greater the influence of $x$ on $y$.

This paper uses geodetection for detecting the factors that influence soil erosion in the loess hilly-gully region of northern Shaanxi Province, quantitatively analyzing the influence each factor has on soil erosion, and determining whether combinations of factors promote soil erosion. To characterize the influence of the various factors affecting soil erosion and determine the main factors that drive soil erosion and the mechanisms of interacting factors, we analyzed land coverage, population, and GDP data from different years with constant soil erosion conditions.

\section{Results and analysis}

\subsection{Analysis of the spatial variation in soil erosion}

Soil erosion is the result of interactions among several geographic elements that may promote or inhibit soil erosion. The strength of soil erosion is defined by the quantity of earth's crust per unit area, per unit time, that is eroded and transported away by natural (hydraulic, wind, gravity, freezing and thawing, etc.) and human activities. It is measured in tons per square kilometer per annum $\left[\mathrm{t} /\left(\mathrm{km}^{2} \cdot \mathrm{a}\right)\right]$. Another way to measure soil erosion is simply to use the change in the elevation at a given point in millimeters per year ( $\mathrm{mm} / \mathrm{a})$. To classify the strength of soil erosion, we use allowable erosion and national maximum erosion as the two extreme values. Between these two extremes, there are six nationally standardized levels of erosion: slight, minor, moderate, intense, very intense, and extreme.

China is a large country with complex natural conditions. Each region has its own major causes of erosion. The nature of erosion varies significantly from place to place. That is to say, we can categorize soil erosion into three major types: hydraulic erosion, wind erosion, and freeze/thaw erosion. In the loess hilly-gully region of northern Shaanxi Province, erosion is mainly caused by flowing water and precipitation, so it can be classified as hydraulic erosion.

The soil erosion data used in this paper come from the resources and environmental science data center of the Chinese Academy of Sciences. The spatial distribution data for soil erosion is formatted according to the Soil Erosion Classification and Grading Standards (MWRPRC, 1997). By extraction and classification of the soil erosion spatial distribution 
data from the study area, we obtain the following soil erosion spatial distribution data for the loess hilly-gully region of northern Shaanxi Province.

Soil erosion in the research zone is divided into six grades. Figure 2 shows clear spatial variation. Areas with relatively minor erosion are Ganquan County, southern Baota District, and southern Zhidan County. Areas with extreme soil erosion are mainly in the north and east, including Jiaxian County, Suide County, Mizhi County, Zizhou County, Wubao County, and Zichang County. We see sporadically distributed minor-to-extreme soil erosion in Zhidan County, Wuqi County, Ansai County, and northern Baota District in the western part of the study area.

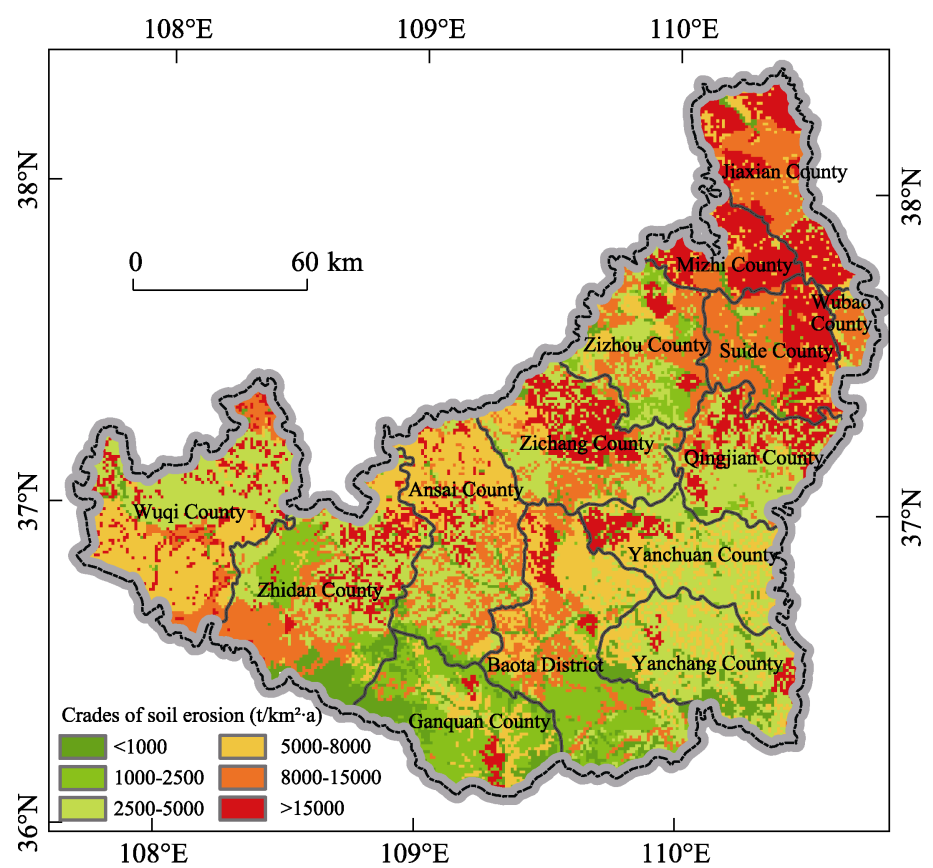

Figure 2 Spatial distribution and grades of soil erosion in the loess hilly-gully region of northern Shaanxi Province in 1995

Quantitative analysis of the erosion level in the study area reveals that grade 3 "moderate" erosion accounts for the largest area of being $26.69 \%$ (Table 1). Next are grade 5 "very intense" areas with $19.52 \%$ and grade 4 "intense" areas with $18.74 \%$. The area of grade 6 "extreme" erosion is $17.22 \%$. Grade 2 "minor" and grade 1 "slight" areas account for relatively little of the area in the research zone, with a sum of $17.81 \%$. The above analysis shows that erosion in the research zone is quite severe. Areas with grades 4 through 6 make up much more than half of the study area. Soil and water conservation work in the research zone is very challenging.

\subsection{Analysis of the primary causes of soil erosion}

Based on geodetection, we analyzed the major causes of spatial variation in soil erosion in the loess hilly-gully region of northern Shaanxi Province. The results (Table 2) show that the major factors, in order of importance, are: population $>$ precipitation $>$ land-use type $>$ elevation $>$ soil type $>$ soil sand content $>$ soil silt content $>$ soil clay content $>$ GDP $>$ slope $>$ aspect. 
Table 1 Quantitative analysis of various soil erosion grades in the loess hilly-gully region of northern Shaanxi Province

\begin{tabular}{clccc}
\hline Grade number & Erosion level & Average erosion modulus $\left(\mathrm{t} / \mathrm{km}^{2} \times \mathrm{a}\right)$ & Area $\left(\mathrm{km}^{2}\right)$ & Proportion $(\%)$ \\
\hline 1 & Slight & $<1000$ & 2618 & 8.07 \\
2 & Minor & $1000-2500$ & 3160 & 9.74 \\
3 & Moderate & $2500-5000$ & 8659 & 26.69 \\
4 & Intense & $5000-8000$ & 6080 & 18.74 \\
5 & Very intense & $8000-15000$ & 6333 & 19.52 \\
6 & Extreme & $>15000$ & 5587 & 17.22 \\
\hline
\end{tabular}

Table 2 Determinants of soil erosion in the loess hilly-gully region of northern Shaanxi Province

\begin{tabular}{lllllll}
\hline $\begin{array}{l}\text { Influencing } \\
\text { factor }\end{array}$ & Population & Precipitation & Land-use type & Elevation & Soil type & Sand content \\
\hline $\begin{array}{l}\text { q value } \\
\begin{array}{l}\text { Influencing } \\
\text { factor }\end{array}\end{array}$ & 0.127102 & 0.102612 & 0.066366 & 0.027132 & 0.018847 & 0.015876 \\
q value & Silt content & Clay content & GDP & Slope & Aspect \\
\end{tabular}

The analysis above indicates that the main factors influencing soil erosion in the loess hilly-gully region of northern Shaanxi Province are human population, precipitation, and land-use type. This is consistent with the results of Wang et al. (1998, 2000, 2008). However, slope and aspect had little effect on soil erosion in our study. This contrasts with the results of Li et al. (2000) and Wang et al. (1998). Observations of small watersheds and simulation results indicate that topographical characteristics like slope and aspect are important factors affecting soil erosion. Also, Wang et al. (1998) and Li et al. (2000) placed slope at the top of the list of factors influencing soil erosion in the loess hilly-gully region of northern Shaanxi Province, followed by precipitation and land use. Many later simulations and studies related to soil erosion in the region have based their analyses and evaluations on the assumption that slope, precipitation, and land use are the main factors influencing soil erosion.

Our analysis discovered that the effects of slope and aspect are unclear. This is related to the limitations of geodetection. Geodetection relies on clear spatial differences in geographical phenomena and interactions between influencing factors. Also, independent variables must be type variables. The topography of the land in the study area is fractured with hills and gullies. Tian et al. (2013) found that the gully density in the Loess Plateau of northern Shaanxi is generally greater than $7 \mathrm{~km} / \mathrm{km}^{2}$, and, in some places, it is greater than $10 \mathrm{~km} / \mathrm{km}^{2}$. The unusually fractured topographic characteristics make it difficult to extract clear spatial variations and an agglomeration of slope and aspect based on DEM data. Therefore, geodetection methods cannot easily analyze the effects of slope and aspect on soil erosion.

The interaction survey (Table 3) in geodetection is used to identify the mechanisms by which risk factors interact. It analyzes the effect of combining risk factors on their ability to explain dependent variables and thereby judges the mechanisms by which pairs of risk factors affect dependent variables. Interaction survey results show that, compared with their individual effects, combinations of precipitation, population, land-use type, and elevation are much more potent. This shows that soil erosion prevention and control efforts must not 
simply address the major risk factors but approach the problem from a holistic, regional perspective.

Table 3 Factor interaction survey results matrix in the loess hilly-gully region of northern Shaanxi Province

\begin{tabular}{lccccc}
\hline & Precipitation & Land-use type & Population & Soil type & Elevation \\
\hline Precipitation & 0.1026 & - & - & - & - \\
Land-use type & 0.1534 & 0.0664 & - & - & - \\
Population & 0.2062 & 0.1805 & 0.1271 & - & - \\
Soil type & 0.1207 & 0.0895 & 0.1441 & 0.0188 & - \\
Elevation & 0.1318 & 0.0940 & 0.1882 & 0.0538 & 0.0271 \\
\hline
\end{tabular}

Note: Due to space limitations, the table only displays a portion of the interaction results.

\subsection{Time dependency of the effects of driving factors on soil erosion}

Using data series from 1995, 2000, 2005, 2010, and 2015, we discovered that, by using soil erosion data as the dependent variable and land coverage data as the independent variable in the geodetection force of determination analysis, soil erosion was progressively less dependent on the effects of land coverage ( $q$ value). The statistical information about the area of each type of land use in the study area (Table 4) indicates that as the blend of land-use types changes, the magnitude of the effect of land use on soil erosion is also changing. Referring to related data, we can see that there are significant differences in the resistance to soil erosion in the Loess Plateau region based on different land-use types. In order of decreasing resistance to erosion, the land-use types are: forest $>$ grassland $>$ wetland $>$ urban infrastructure $>$ unused land $>$ cultivated land.

Table 4 The effect of land coverage changes on the $q$ value in the loess hilly-gully region of northern Shaanxi Province

\begin{tabular}{ccccccccc}
\hline Year & $q$ value & $\begin{array}{c}\text { Cultivated } \\
\text { land area } \\
\left(\mathrm{km}^{2}\right)\end{array}$ & $\begin{array}{c}\text { Forested } \\
\text { area }\left(\mathrm{km}^{2}\right)\end{array}$ & $\begin{array}{c}\text { Grassland } \\
\text { area }\left(\mathrm{km}^{2}\right)\end{array}$ & $\begin{array}{c}\text { Wetland } \\
\text { area }\left(\mathrm{km}^{2}\right)\end{array}$ & $\begin{array}{c}\text { Urban and indus- } \\
\text { trial infrastructure } \\
\text { area }\left(\mathrm{km}^{2}\right)\end{array}$ & $\begin{array}{c}\text { Unused } \\
\text { land }\left(\mathrm{km}^{2}\right)\end{array}$ & $\begin{array}{c}\text { Ratio of forest } \\
\text { and grassland } \\
(\%)\end{array}$ \\
\hline 1995 & 0.066 & 16100 & 4080 & 17204 & 233 & 124 & 59 & 55.22 \\
2000 & 0.059 & 16669 & 4695 & 16834 & 202 & 80 & 64 & 55.86 \\
2005 & 0.049 & 15790 & 5638 & 16754 & 201 & 97 & 64 & 58.09 \\
2010 & 0.048 & 15712 & 5727 & 16745 & 198 & 98 & 64 & 58.30 \\
2015 & 0.047 & 15759 & 5688 & 16649 & 203 & 135 & 110 & 57.95 \\
\hline
\end{tabular}

The land coverage change patterns in the Loess Plateau of northern Shaanxi Province from 1995 to 2015 showed (Table 4) that, the area of cultivated land, grassland, and wetland in the region decreased. Over that 20-year period, the cultivated land area decreased by 341 $\mathrm{km}^{2}$, grassland decreased by $555 \mathrm{~km}^{2}$, and wetland area decreased by $30 \mathrm{~km}^{2}$. Forested area, urban infrastructure area, and unused land area all increased. Over that 20-year period, forested area increased by $1608 \mathrm{~km}^{2}$, urban infrastructure area increased by $11 \mathrm{~km}^{2}$, and unused land area increased by $51 \mathrm{~km}^{2}$. If we look at the ratio of forest and grassland in the study area, we see that it increases from $55.22 \%$ in 1995 to $57.95 \%$ in 2015 . 
This means that there is a negative correlation between the area of forest and grassland and severe soil erosion. That is, increasing the proportion of forest and grassland in the study area helps increase the region's resistance to soil erosion. Therefore, by converting fields to forests and grasslands, the severity of soil erosion in the loess hilly-gully region of northern Shaanxi Province can be effectively mitigated. Converting fields to forests and grasslands helps protect the region's ecosystems and provides a path toward sustainable development.

When we analyze the population and GDP data from 1995, 2000, 2005, and 2015 in the same way, we discover that, as population and GDP increase, the $q$ value corresponding to population and GDP also decreases. Referring to related data, we discover that, as urbanization in China continues, the population is becoming more concentrated in urban areas. Combined with rapid economic development, this means that urban GDP is also on the rise. In the loess hilly-gully region of northern Shaanxi Province, urban areas are mainly distributed in flat, open areas. Also, urban planners are becoming more concerned about environmental protection. Therefore, although population and GDP have both increased, their combined effects have contributed to decreasing soil erosion. This means that, as the degree of urbanization continues to rise, the human population continues to become more concentrated in urban areas. Economic production thus becomes more efficient, which is beneficial to the region's ecological conservation.

\section{Discussion}

Most current research on soil erosion in the loess hilly-gully region is based on data from point observations, models of sediment production from slopes, and watershed-scale modeling. There is relatively little research on the dominant factors influencing soil erosion on a regional scale. This paper carried out geodetection analysis using soil erosion datasets from 1995 through 2015. With soil erosion as the dependent variable, and human population, land-use type, multi-year precipitation, topography, soil data, etc. from the same year as independent variables, we studied the driving factors of soil erosion on a regional scale. We revealed the individual and pairs of driving factors that most influenced soil erosion to enrich the body of research on soil erosion in the region.

However, there is room for further study to make our results more complete. (1) The factor selection and methods did not completely consider the spatial scale and special characteristics of the topography in the study area. This caused some of the known driving factors of erosion (slope and aspect) to have no significant effects in our regional-scale geodetection analysis. This result contradicts the results of other studies. This is a problem of spatial scale that needs to be addressed in future studies of soil erosion in the loess hilly-gully region of northern Shaanxi Province. (2) The interaction analysis based on geodetection can only evaluate the interaction of pairs of risk factors. The simultaneous interactions of more than two factors cannot be effectively analyzed. Therefore, future researchers may choose to use different methods and models to analyze the driving factors and mechanisms of soil erosion. Also, the interaction mechanisms revealed in this paper are for regional-scale interactions. Their connections with driving factor mechanisms at the watershed scale need to be analyzed in more depth. 


\section{Conclusions}

This paper studied the major factors driving soil erosion in the loess hilly-gully region of China's northern Shaanxi Province. We analyzed these factors and their interactions using geodetection and spatial variation. We confirmed the statistically significant driving forces behind soil erosion and looked at the relative influence of population, land-use type, GDP, etc. at different period of time. We explored the changes in the ways that the driving factors affect soil erosion over time. Our study shows:

(1) Soil erosion in the loess hilly-gully region of northern Shaanxi is mainly hydraulic erosion. It is divided into six levels of severity: slight, minor, moderate, intense, very intense, and extreme. Among them, the extreme, intense and very intense eroded areas are 18,000 $\mathrm{km}^{2}$, accounting for $55.48 \%$ of the total land area, and the slight and minor eroded areas are $5778 \mathrm{~km}^{2}$, accounting for $17.81 \%$. There is significant spatial variation in the severity of soil erosion. It is relatively less severe in the south and more extreme in the north. The center and west are intermediately eroded.

(2) Using geodetection survey analysis, we determined that the main driving factors behind soil erosion in the loess hilly-gully region of northern Shaanxi have both natural and artificial elements. They are: human population, precipitation, land-use type, soil type, elevation, sand content of the soil, etc. The spatial distribution of the human population had the greatest effect. The $q$ value was 0.127 . Next was precipitation with a $q$ value of 0.103 . Factor interaction analysis revealed that pairs of factors, such as the spatial distribution of the human population, precipitation, land-use type, slope, etc. had synergistic mechanisms. That is, the soil erosion effects of certain combinations were more severe than the sum of their individual effects. For example, the $q$ value of single factor of precipitation is 0.1026 , however, when precipitation factor works with land-use type, population, soil type and elevation factors the $q$ values are $0.1534,0.2062,0.1206$, and 0.1318 , which are higher than the former.

(3) The impact of land cover change on soil erosion has been reduced from 0.066 to 0.047 between 1995 and 2015. Changes in the proportions of land-use types over time have led to decreasing soil erosion. Analysis showed that this is related to an increase in the proportion of vegetation coverage in the study area over time with positive ecological effects. Further analysis showed that, while the human population and GDP have continued to increase in the region, urbanization has led to a more spatially concentrated human population and GDP production, with clear benefits to both ecological preservation and sustainable development.

(4) Ecological protection measures such as returning farmland to forests and grasses can effectively reduce the degree of soil erosion in the loess hilly-gully region of northern Shaanxi. According to the land cover change data of the study area (Table 4), the areas of cultivated land, grassland, and wetland in the region decreased during 1995-2015, and forested area, urban infrastructure area, and unused land area were all increased. The forest land increased by $1608 \mathrm{~km}^{2}$ in the 20 years. The proportion of forest and grassland area in the study area increased from $55.22 \%$ in 1995 to $57.95 \%$ in 2015 . These changes indicate that the proportion of ecological land area such as forest and grassland is negatively correlated with the severity of soil erosion. According to the existing research results, the anti-erosion ability of forest land in the Loess Plateau is the strongest. Therefore, the policies of returning farmland to forest and grassland plays an important role in improving soil anti-erosion capability and in preventing soil loss. 


\section{References}

Cao F, Ge Y, Wang J F, 2013. Optimal discretization for geographical detectors-based risk assessment. GIS Science \& Remote Sensing, 50(1): 78-92.

Cao Z, Li Y R, Liu Y S et al., 2017. When and where did the Loess Plateau turn "green"? Analysis of the tendency and breakpoints of normalized difference vegetation index. Land Degradation and Development, 1-14.

Ding W F, Huang C H, 2017. Effects of soil surface roughness on interrill erosion processes and sediment particle size distribution. Geomorphology, 295: 801-810.

Dong Y X, Xu Q, Yang R et al., 2017. Delineation of the northern border of the tropical zone of China's mainland using Geodetector. Acta Geographica Sinica, 72(1): 135-147. (in Chinese)

Fu J Y, Jiang D, Huang Y H, 2014. $1 \mathrm{~km}$ grid population dataset of China (Population Grid_China), Global Change Research Data Publishing \& Repository. doi: 10.3974/geodb.2014.01.06.V1. (in Chinese)

Gao H D, Li Z B, Li P et al., 2015. The capacity of soil loss control in the Loess Plateau based on soil erosion control degree. Acta Geographica Sinica, 70(9): 1503-1515. (in Chinese)

Han J C, Liu Y S, Zhang Y G, 2015. Sand stabilization effect of feldspathic sandstone during the fallow period in Mu Us Sandy Land. Journal of Geographical Sciences, 25(4): 428-436.

Hu Y, Wang J F, Li X H et al., 2011. Geographical detector-based risk assessment of the under-five mortality in the 2008 Wenchuan earthquake, China. PloS One, 6(6): e21427.

Huang Y H, Jiang D, Fu J Y, 2014.1 km grid GDP data of China (2005, 2010) (GDPGrid_China), Global Change Research Data Publishing \& Repository. doi: 10.3974/geodb.2014.01.07.V1.

Li X W, Xie Y F, Wang J F et al., 2013. Influence of planting patterns on fluoroquinolone residues in the soil of an intensive vegetable cultivation area in north China. Science of the Total Environment, 458-460: 63-69.

Li Y, Zhang J H, Yang J C et al., 2000. Spatial patterns of soil erosion on steep cultivated hillslope in Loess Plateau of Northern Shaanxi. Journal of Soil and Water Conservation, 14(4): 17-21. (in Chinese)

Liang P, Yang X P, 2016. Landscape spatial patterns in the Maowusu (Mu Us) Sandy Land, northern China and their impact factors. Catena, 145: 321-333.

Liu G B, Wang B, Wei W, 2016. Technique and demonstration of water and soil loss comprehensive harness on the Loess Plateau. Acta Ecologica Sinica, 36(22): 7074-7077. (in Chinese)

Liu J Y, Kuang W H, Zhang Z X et al., 2014. Spatiotemporal characteristics, patterns and causes of land-use changes in China since the late 1980s. Journal of Geographical Sciences, 24(2): 195-210.

Liu J Y, Zhang Z X, Xu X L et al., 2010. Spatial patterns and driving forces of land use change in China during the early 21st century, Journal of Geographical Sciences, 20(4): 483-494.

Liu Y S, 2018. Introduction to land use and rural sustainability in China. Land Use Policy, 74(5):1-4.

Liu Y S, Fang F, Li Y H, 2014. Key issues of land use in China and implications for policy making. Land Use Policy, 40(4): 6-12.

Liu Y S, Li J T, 2017. Geographic detection and optimizing decision of the differentiation mechanism of rural poverty in China. Acta Geographica Sinica, 72(1): 161-173. (in Chinese)

Liu Y S, Li Y H, 2017. Revitalize the world's countryside. Nature, 548(7667): 275-277.

Liu Y S, Yang R, 2012. The spatial characteristics and formation mechanism of the county urbanization in China. Acta Geographica Sinica, 67(8): 1011-1020. (in Chinese)

Liu Z J, Liu Y S, Li Y R, 2018a. Anthropogenic contributions dominate trends of vegetation cover change over the farming-pastoral ecotone of northern China. Ecological Indicators, 95(1): 370-378.

Liu Z J, Liu Y S, Li Y R, 2018b. Extended warm temperate zone and opportunities for cropping system change in the Loess Plateau of China. International Journal of Climatology, 38(11): 1-12.

Liu Z J, Liu Y S, Wang S S et al., 2018c. Evaluation of spatial and temporal performances of ERA-interim precipitation and temperature in mainland of China. Journal of Climate, 31(11): 4347-4365.

Luo W, Jasiewicz J, Stepinski T et al., 2016. Spatial association between dissection density and environmental factors over the entire conterminous United States. Geophysical Research Letters, 43(2): 692-700.

Meng Q X, Liu G B, Yang Q K, 2008. Soil erosion change on the Loess Plateau. Research of Soil and Water 
Conservation, 15(3): 20-22. (in Chinese)

Meng X Y, Shi C X, Liu S Y, 2016a. CMADS datasets and its application in watershed hydrological simulation: A case study of the Heihe River Basin. Pearl River, 37(7): 1-19. (in Chinese)

Meng X Y, Wang H, Cai S et al., 2016b. The China Meteorological Assimilation Driving Datasets for the SWAT Model (CMADS) Application in China: A case study in Heihe River Basin. Preprints, 2016: 120091. doi: 10.20944/preprints201612.0091.v2.

Meng X Y, Wang H, Lei X H et al., 2017. Hydrological Modeling in the Manas River Basin using soil and water assessment tool driven by CMADS. Tehnicki Vjesnik - Technical Gazette, 24(2): 525-534. doi: 10.17559/TV-20170108133334.

Ministry of Water Resources of the People's Republic of China (MWRPRC), 1997. Standards for Classification and Gradation of Soil Erosion, SL190-96. (in Chinese)

Shi C X, Xie Z H, Qian H et al., 2011. China land soil moisture EnKF data assimilation based on satellite remote sensing data. Science China Earth Sciences. doi: 10.1007/s11430-010-4160-3.

Tang K L, 2004. China Soil and Water Conservation. Beijing: Science Press. (in Chinese)

Tian J, Tang G A, Zhou Y et al., 2013. Spatial variation of gully density in the Loess Plateau. Scientia Geographica Sinica, 33(5): 622-628. (in Chinese)

Wang J F, Li X H, Christakos G et al., 2010. Geographical detectors-based health risk assessment and its application in the neural tube defects study of the Heshun region, China. International Journal of Geographical Information Science, 24(1): 107-127.

Wang J F, Xu C D, 2017. Geodetector: Principle and prospective. Acta Geographica Sinica, 72(1): 116-134. (in Chinese)

Wang J F, Zhang T L, Fu B J, 2016. A measure of spatial stratified heterogeneity. Ecological Indicators, 67: $250-256$.

Wang W J, 2016. Assessment of sensitivity of water and soil loss on the Loess Plateau in North Shaanxi Province [D]. Xi'an: Northwest University. (in Chinese)

Wang Z L, 2000. Analyses of affecting factors of soil erosion and its harms in China. Transactions of the Chinese Society of Agricultural Engineering, 16(4): 32-36. (in Chinese)

Wang Z L, Jin X Y, Ma C Y et al., 2008. Research on processes and responses of rainfall-runoff-sediment yield on loess hillslope. Journal of Soil and Water Conservation, 22(2): 24-28. (in Chinese)

Wang Z L, Shao M A, 1998. Soil erosion characters of slope land in the 2nd sub-region of Loess Plateau. Research of Soil and Water Conservation, 5(4): 11-21, 97. (in Chinese)

Wang Z L, Shao M A, Chang Q R, 1998. Effects of rainfall factors on soil erosion in Loess Plateau. Journal of Northwest A \& F University (Natural Science Edition), 26(4): 106-110. (in Chinese)

Wu R N, Zhang J Q, Bao Y H et al., 2016. Geographical detector model for influencing factors of industrial sector carbon dioxide emissions in Inner Mongolia, China. Sustainability, 8(2): 149.

Yang R, Liu Y S, Long H L et al., 2016. Spatial distribution characteristics and optimized reconstructing analysis of rural settlement in China. Scientia Geographica Sinica, 36(2): 170-179. (in Chinese)

Zheng F L, Tang K L, Zhang K L et al., 1995. Relationship of eco-environment change and natural erosion and man-made accelerated erosion. Acta Ecologica Sinica, 15(3): 251-259. (in Chinese)

Zhong L N, Wang J, Zhao W W, 2017. Comparative analysis of the effect of rainfall pattern and land use pattern on soil erosion in different-scale watersheds: A case study in hilly and gully area of the Loess Plateau. Acta Geographica Sinica, 72(3): 432-443. (in Chinese)

Zhu H, Liu J M, Tao H, 2015. Temporal-spatial pattern and contributing factors of urban RBDs in Beijing. Acta Geographica Sinica, 70(8): 1215-1228. (in Chinese) 